\title{
AVALIAÇÃO DO CRESCIMENTO E DA UTILIZAÇÃo DE NUTRIENTES PELO AMENDOIM
}

\author{
C.T. FEITOSA \\ Seção de Fertilldade do Solo e Nutrị̧ão de Plantas - IAC - C.P. 28, CEP: 13001-970 - Campinas,SP. \\ S.S.S. NOGUEIRA \\ Seçāo de Fisiologia - IAC - C.P. 28, CEP: 13001-970 - Campinas,SP. \\ M.A.N. GERIN; F.S.O. RODRIGUES FILHO \\ Seção de Oleaginosas - IAC - C.P. 28, CEP: 13001-970 - Campinas,SP.
}

RESUMO: Avaliaram-se os padrōes de crescimento e de absorção de macro e de micronutrientes de quatro cultivares de amendoim, sendo três de lançamento recente, IAC-Oirā, IAC-Poitara e IAC-Tupã, todos de porte ereto e um mais antigo, Penápolis, de hábito rasteiro. Os resultados obtidos mostraram que os cultivares recentes apresentaram o mesmo padrão de crescimento e de acúmulo dos nutrientes e o cultivar a rasteiro, de ciclo mais longo, apresentou um padrão ligeiramente diferente. Dentre os cultivares estudados, IAC-Tupã e IAC-Oirã apresentaram certa superioridade na eficiência de aproveitamento da matéria seca total produzida e do total de nutrientes translocados para a semente, órgão alvo da cultura do amendoim.

Descritores: amendoim, cultivares, parâmetros de crescimento, marcha de absorção.

\section{PEANUT GROWTH AND NUTRIENT USE EVALUATION}

SUMMARY: Plant growth and mineral absorption of four peanut cultivars were evaluated, three of them being new erect cultivars, IAC-Oirã, IAC-Poitara and IAC-Tupã, and the fourth, Penápolis an old creeper cultivar. The new cultivars had the same growth and nutrient absorption patterns. The cultivar Penapolis showed small differences specially due to cicle size. The new cultivars, IAC-Tupã and IAC-Oirā showed better efficiency in transporting to seeds the produced dry matter and nutrients, the target organ in a peanut crop.

Key Words: peanut, cultivars, growth parameters, mineral absorption.

\section{INTRODUÇÃO}

A fisiologia da produção de uma cultura É um tópico importante sob o ponto de vista econômico e científico. O hábito de crescimento da planta ao longo do ciclo biológico, e a maneira com que a mesma absorve e aproveita os minerais essenciais ao crescimento e à produção, são itens imprescindíveis no estudo de cultivares de qualquer planta de valor econômico. $O$ crescimento da planta em comunidades vegetais pode ser avaliado através de alguns parâmetros, dentre os quais se destacam a produção de matéria seca e sua distribuição na planta ao longo do ciclo biológico e o índice de área foliar. A nutrição mineral é avaliada através de curvas de absorção e translocação dos nutrientes do plantio à produção final.

O acúmulo de matéria seca é uma medida da capacidade do aparelho fotossintético e o índice de área foliar (IAF) descreve o tamanho desse aparelho. Teoricamente, o IAF ótimo seria aquele que suportasse uma taxa máxima de produção de matéria seca. No entanto, quando o produto final não é a biomassa, mas sim grãos, tubérculos, frutos, etc, nem sempre o IAF ótimo coincide com a máxima produção (KVET et al., 1971; HUNT, 1981). Não é um índice inquestionável, mas dá uma idéia da eficiência da planta em estudo.

O Instituto Agronômico de Campinas, procurando aumentar a produtividade do amendoim, tem lançado novos cultivares comerciais (POMPEU, 1987). Sobre esses cultivares, não são conhecidas as características fisiológicas e nutricionais.

O objetivo do presente estudo é o de quantificar a produção, acúmulo e distribuição da matéria seca e o acúmulo e translocação de nutrientes ao longo do ciclo biológico de três novos cultivares de amendoim (Arachis hipogaea L.), IAC-Oirã, IAC-Poitara e IAC-Tupã e um cultivar mais antigo, Penápolis. 


\section{MATERIAL E MÉTODOS}

O presente experimento foi instalado no Centro Experimental de Campinas, em um Latossolo Vermelho Escuro, álico, com textura moderada, em área irrigada. A cultura recebeu calagem e adubação, segundo recomendações técnicas de PEDRO JR. et al., (1987).

Foram utilizados três cultivares de lançamento recente, IAC-Oirã, IAC-Tupã e IAC-Tupã, todos de porte ereto, com ciclos semelhantes (110-120 dias) e do grupo Virgínia (POMPEU, 1987), e um cultivar mais antigo, Penápolis, de porte rasteiro, também do grupo Virgínia, com ciclo de 150 dias. O delineamento experimental utilizado foi $o$ de blocos ao acaso com 4 repetições, somando 16 parcelas, compostas cada uma de 5 linhas de $10 \mathrm{~m}$ de comprimento espaçadas de $0,60 \mathrm{~m}$. As plantas foram semeadas no dia 10/12/88. Após a germinação, aos $15,30,45,60$, 85,100 e 110 dias para os cultivares eretos e aos $15,30,45,60,85,100$ e 150 para o cultivar Penápolis, foram colhidas amostras de cada parcela. Cada amostra era constituída por todas as plantas contidas em um metro linear, escolhido em cada época de amostragem, nas 3 linhas centrais da parcela, sempre entre espaços lineares não colhidos anteriormente, nas linhas vizinhas.

As plantas foram lavadas e separadas em folhas, ramos, vagens e sementes. A área foliar, para cálculo do índice de área foliar, foi calculada pelo método de discos de diâmetro conhecido, com as folhas ainda frescas. Após esta operação, o material foi seco em estufa à $60^{\circ} \mathrm{C}$. O material seco foi pesado, sendo então obtidos os pesos da matéria seca das partes avaliadas. Após esta operação, o material foi moído e analisado quanto aos teores de macro e micronutrientes, segundo os métodos descritos por BATAGLIA et al. (1983).

$O$ cálculo das quantidades de nutrientes absorvidos e acumulados pelos cultivares de amendoim foi feito com base no peso da matéria seca das partes e respectivos teores em cada época.

O cálculo da matéria seca por unidade de área foi feito tendo como base uma população de 166.000 plantas/ha.

\section{RESULTADOS E DISCUSSÃO}

Índice de área foliar e acúmulo de matéria seca

Os valores dos índices de área foliar nas diferentes épocas do ciclo biológico, para os quatro cultivares em estudo, são apresentados na TABELA 1. Observou-se que na primeira amostragem, aos 15 dias, o IAF não variou entre os cultivares. Os cultivares eretos apresentaram valor máximo aos 80 dias e o IAC-Penápolis, aos 100 dias. O cultivar IAC-Poitara apresentou maior IAF, seguido em ordem decrescente por IAC-Oirã, Penápolis e IACTupã. A produção de matéria seca das partes das plantas bem como das sementes, apresentados na TABELA 2, são valores importantes na interpretação do IAF. Verificou-se que o cultivar IAC-Tupã, que apresentou uma maior produção de sementes, atingiu o menor IAF na Época de maior produção de matéria seca de folhas. Já o cultivar IAC-Poitara, que atingiu o maior IAF, apresentou uma produção de sementes $8,4 \%$ menor do que o cultivar IAC-Tupã. No entanto, a quantidade total de matéria seca produzida pelo IAC-Poitara foi $8,12 \%$ maior que o IAC-Tupã. Os resultados indicam que o cultivar IAC-Poitara deva ser menos eficiente na utilização dos produtos da fotossíntese para a semente, utilizando-as na formação de caules.

O porcentual da matéria seca total utilizado pelos cultivares para a formação de grãos, apresentado na TABELA 3 , segue a ordem decrescente: IAC-Tupã > IAC-Oirã > Penápolis $>$ IAC-Poitara. Os cultivares IAC-Tupã e IAC-Oirã apresentam valores bem próximos, indicando uma eficiência produtiva mais alta.

Observando as Figuras 1, 2, 3 e 4, verifica-se que $\circ$ padrão de crescimento e a partição da matéria seca são os mesmos para os cultivares eretos, ou seja, a matéria seca produzida pelas folhas atinge o valor máximo aos 85 dias, decrescendo em seguida; a matéria seca produzida pelos caules atinge o valor máximo aos 100 dias decrescendo em seguida; no ponto de máxima produção de matéria seca de folhas, tem início o processo de formação dos órgãos reprodutivos (vagens e grãos), cujo final é a colheita. $O$ cultivar Penápolis, de hábito rasteiro, apresentou um padrão de crescimento diferente. A máxima produção de matéria seca de folhas ocorre aos 100 dias, porém a de caules, ocorre antes, aos 80 dias, época em que teve início o período reprodutivo, ou seja, a formação de vagens e grãos.

A produção de sementes dos cultivares, foi a seguinte em ordem decrescente: IAC-Tupã $(2400 \mathrm{~kg} / \mathrm{ha})>$ IAC-Oirã $(2350 \mathrm{~kg} / \mathrm{ha})>$ IAC-Poitara (2200kg/ha) > Penápolis (1998kg/ha). Esses valores são semelhantes aos citados por 


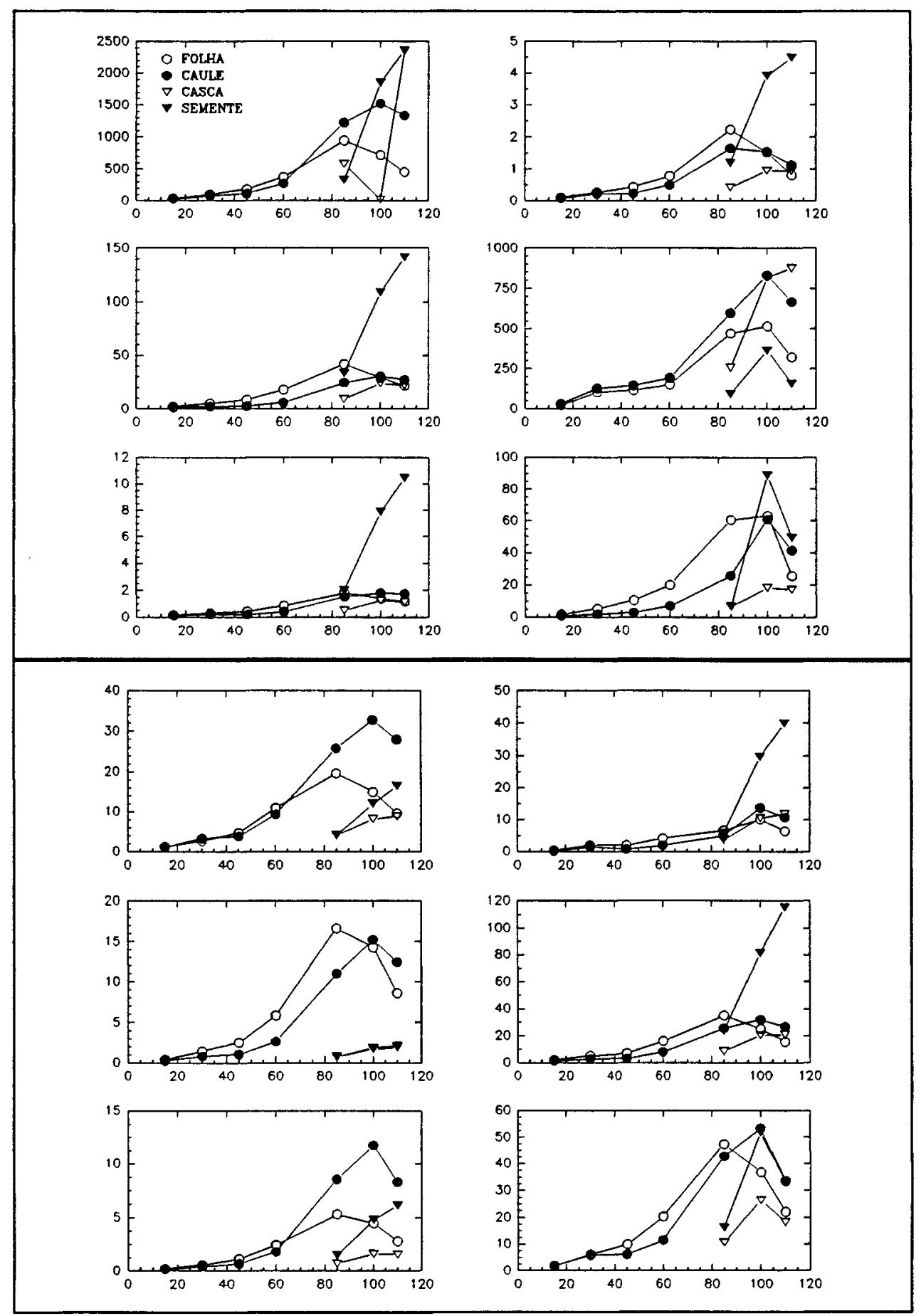

Figura 1 - Acúmulo de matéria seca e de macro e micronutrientes em várias épocas de desenvolvimento da planta de amendoim.

Cultivar IAC-Oirã 


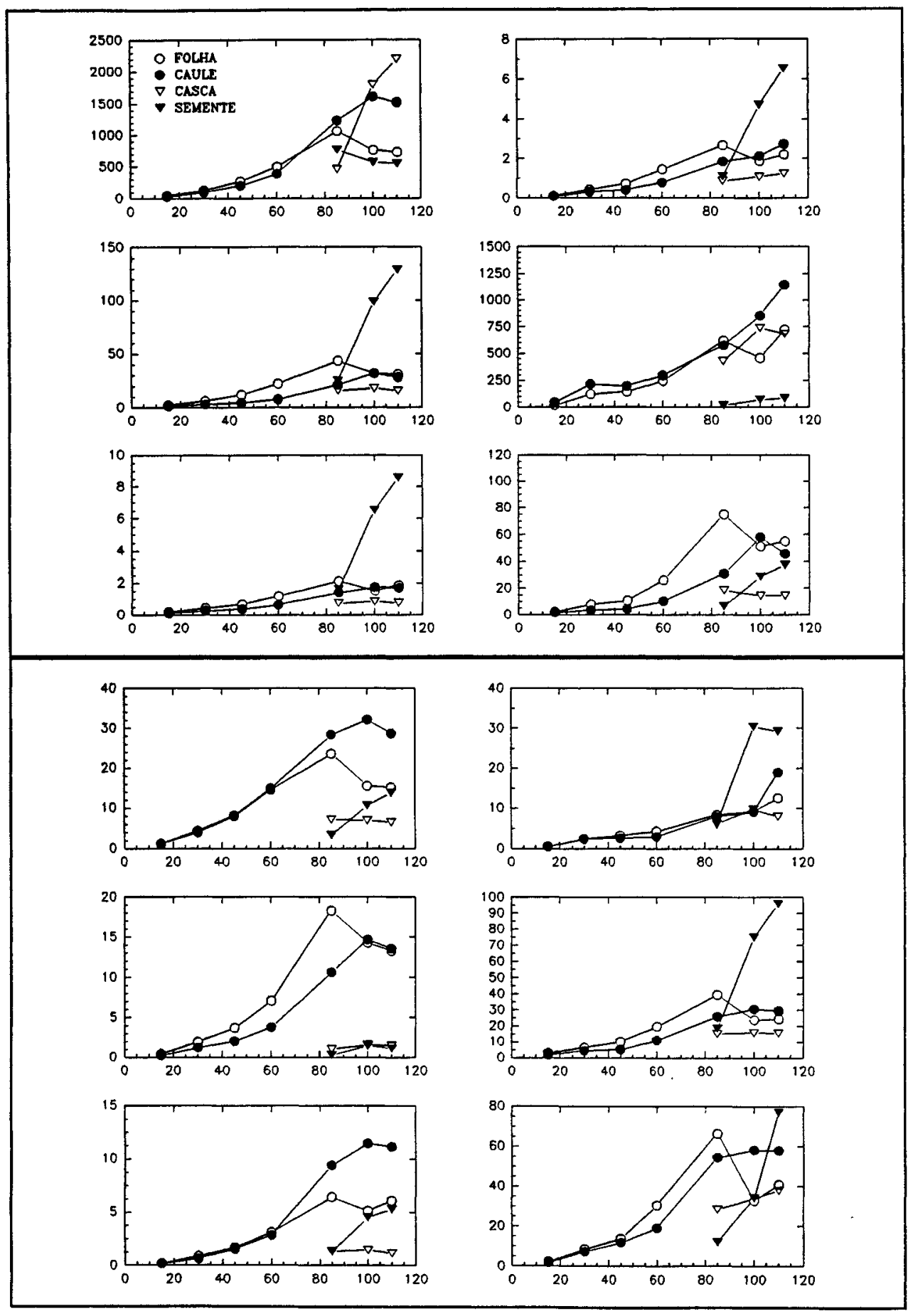

Figura 2 - Acúmulo de matéria seca e de macro e micronutrientes em várias épocas de desenvolvimento da planta de amendoim.

Cultivar IAC-Poitara

Sci. agric., Piracicaba, 50(3):427-437, out./dez., 1993 


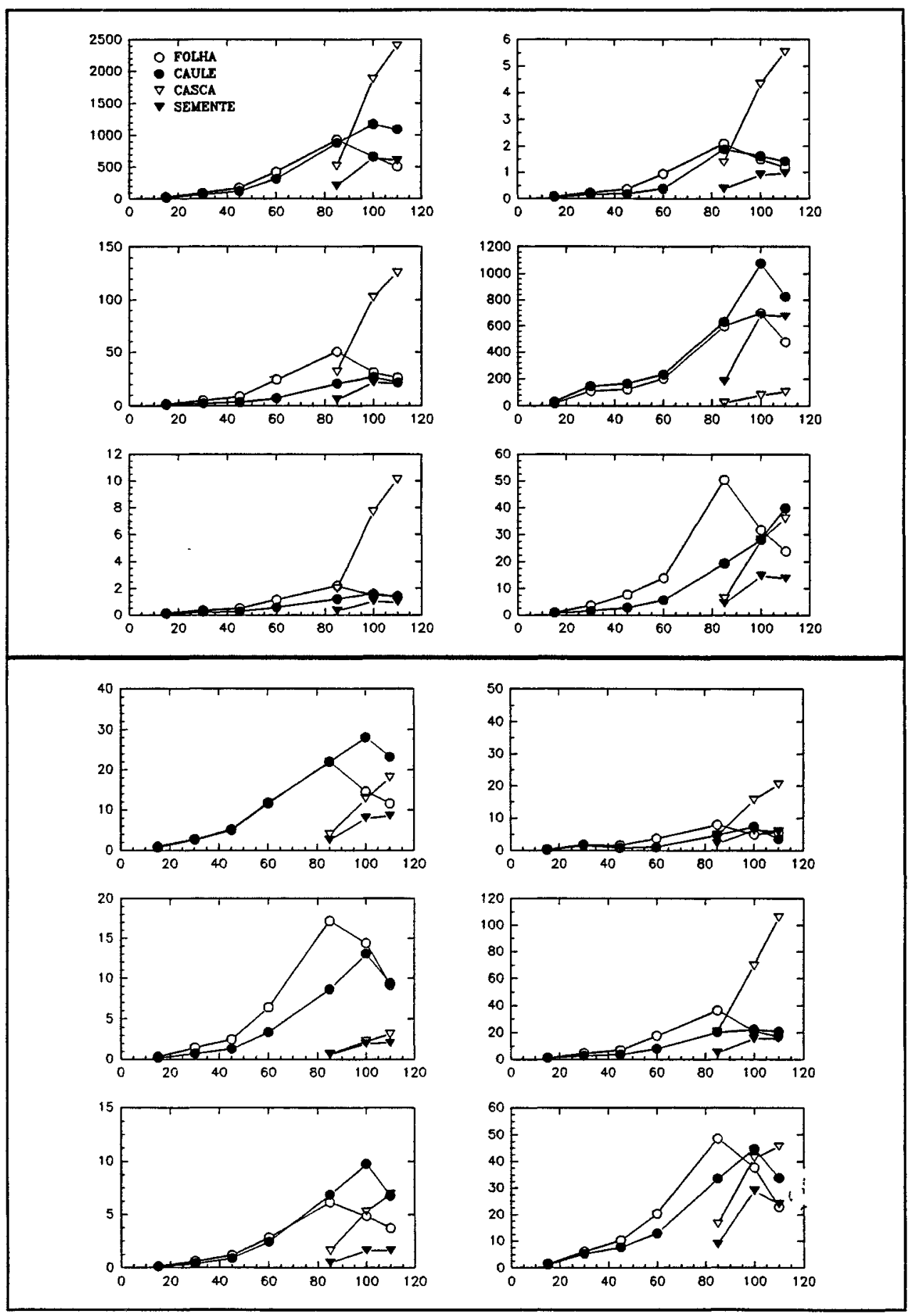

Figura 3 - Acúmulo de matéria seca e de macro e micronutrientes em várias épocas de desenvolvimento da planta de amendoim.

Cultivar IAC-Tupã 

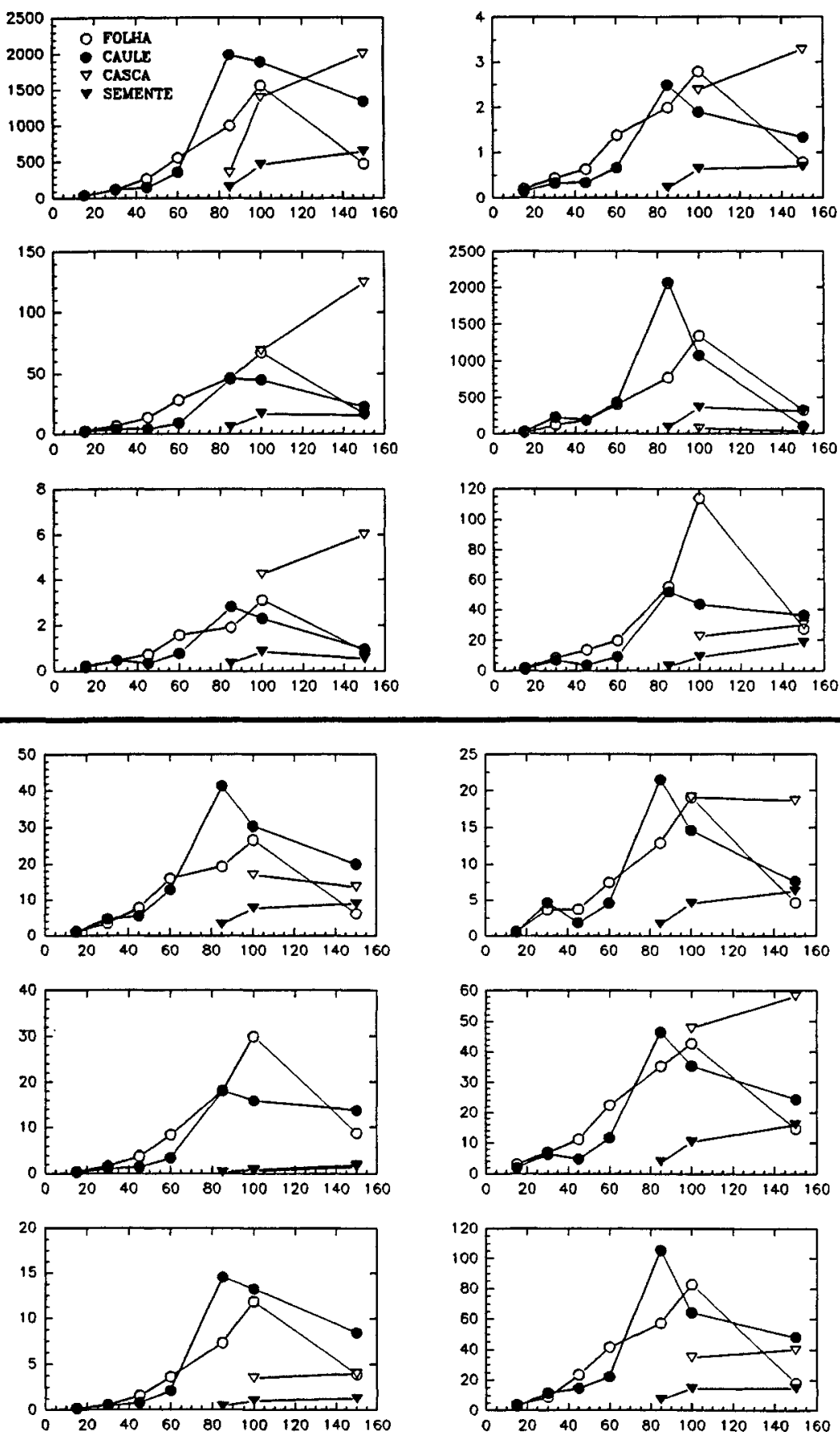

Figura 4 - Acúmulo de matéria seca e de macro e micronutrientes em várias épocas de desenvolvimento da planta de amendoim.

Linhagem Penápolis

Sci. agric., Piracicaba, 50(3):427-437, out./dez., 1993 
TABELA 1. Índice de Área Foliar (IAF) de quatro cultivares de amendoim, em diferentes épocas do ciclo biológico da cultura (média de 4 repetições).

\begin{tabular}{lcccccccc}
\hline \hline & \multicolumn{8}{c}{ Índice de Área Foliar } \\
\cline { 2 - 9 } Cultivar & 15 & 30 & 45 & 60 & 80 & 100 & 110 & 150 \\
\hline Oirã & 0,06 & 0,14 & 0,49 & 0,95 & 2,32 & 1,68 & 1,32 & - \\
Poitira & 0,07 & 0,19 & 0,62 & 1,12 & 2,49 & 1,86 & 0,86 & - \\
Tupã & 0,05 & 0,14 & 0,29 & 0,70 & 1,58 & 1,00 & 0,73 & - \\
Penápolis & 0,06 & 0,19 & 0,55 & 1,10 & 1,93 & 2,39 & - & 0,38 \\
\hline \hline
\end{tabular}

POMPEU et al. (1986) para cultivares e linhagens com boa produtividade, bem como para os mesmos cultivares do presente estudo (POMPEU, 1987). A diferença de produção entre o mais produtivo (IAC-Tupã) e o menos produtivo (Penápolis) foi de $402 \mathrm{~kg}$, o que corresponde a uma diferença de $16,75 \%$.

\section{Absorção e acúmulo de macronutrientes}

As quantidades de macronutrientes absorvidas por unidade de área pelas diversas partes dos quatro cultivares em estudo são apresentadas na TABELA 2 e suas marchas de absorção representadas nas Figuras 1, 2, 3 e 4 . A mobilização dos nutrientes para a semente é apresentada na TABELA 3.

Nos cultivares eretos a máxima absorção de nitrogênio coincidiu com a máxima produção de matéria seca pela parte aérea, ou seja, aos 85 dias. Os cultivares absorveram nitrogênio na seguinte ordem: IAC-Oirã $(213 \mathrm{~kg} / \mathrm{ha})>$ IAC-Poitara $(204 \mathrm{~kg} / \mathrm{ha})>$ Penápolis $(180 \mathrm{~kg} / \mathrm{ha})>$ IAC-Tupã $(172 \mathrm{~kg} / \mathrm{ha})$. Os cultivares estudados apresentaram variação muito pequena na porcentagem de nitrogênio total absorvida e mobilizada para a semente, ou seja, desde $61 \%$ no cultivar IAC-Tupã até $68 \%$ no Cultivar Penápolis (TABELA 3).

O fósforo foi absorvido pelos cultivares na seguinte ordem: IAC-Oirã $(14 \mathrm{~kg} / \mathrm{ha})=$ IAC-Tupã $(14 \mathrm{~kg} / \mathrm{ha})>$ IAC-Poitara (13kg/ha) $>$ Penápolis (10kg/ha). Do total absorvido, o cultivar IAC-Tupã utilizou $73,2 \%$ para a semente; IAC-Oirã utilizou 71,7\%; IAC-Poitara utilizou 66,8\%; e Penápolis, 59,4\% (TABELA 3).

A época de maior absorção pela parte aérea coincidiu com aquela de maior produção de matéria seca da parte aérea, ou seja, até 85 dias para os cultivares eretos e 100 dias para o cultivar rasteiro.

A quantidade de potássio absorvida pelos cultivares de lançamento recente foi aproximadamente a mesma $(62,0 \mathrm{~kg} / \mathrm{ha})$. $O$ cultivar Penápolis absorveu aproximadamente $19 \%$ a menos que os demais (TABELA 2). No entanto, foi o mais eficiente na sua translocação para a semente (TABELA 3).

A quantidade de cálcio acumulada não variou muito entre os cultivares. $O$ cultivar IAC-Tupã absorveu, no total, $23,6 \mathrm{~kg} / \mathrm{ha}$, sendo este o valor extremo inferior (TABELA 2). No entanto, as sementes do cultivar IAC-Tupã apresentaram um maior acúmulo percentual, indicando que o mesmo tem uma maior habilidade na sua absorção, uma vez que o elemento é conhecidamente muito pouco translocado.

Quanto ao magnésio, o cultivar IAC-Poitara acumulou aproximadamente $30 \%$ à mais do que os demais (TABELA 2). No entanto os cultivares IAC-Tupã e IAC-Oirã aproveitaram mais eficientemente o elemento nas sementes do que IAC-Poitara e Penápolis (TABELA 3).

Os cultivares acumularam enxofre na seguinte ordem: IAC-Poitara $(12,6 \mathrm{~kg} / \mathrm{ha})>$ IACTupã $(9 \mathrm{~kg} / \mathrm{ha})>$ IAC-Oirã $(8 \mathrm{~kg} / \mathrm{ha})>$ Penápolis (6kg/ha), segundo a TABELA 2. No entanto, o cultivar IAC-Tupã acumulou nas sementes, $20 \%$ mais do que os demais (TABELA 3). 
TABELA 2. Quantidade acumulada de matéria seca e de macronutrientes, em $\mathrm{kg} / \mathrm{ha}$ pelas diferentes partes da planta de quatro cultivares de amendoim, ao longo do ciclo biológico da cultura (média de 4 repetições).

\begin{tabular}{|c|c|c|c|c|c|c|c|c|}
\hline \multirow[b]{2}{*}{ Cultivares } & \multirow{2}{*}{$\begin{array}{c}\text { Parte da } \\
\text { Planta }\end{array}$} & \multirow{2}{*}{$\begin{array}{c}\text { Matéria } \\
\text { Seca }\end{array}$} & \multicolumn{6}{|c|}{ Nutrientes } \\
\hline & & & $\mathrm{N}$ & $\mathrm{P}$ & $\mathrm{K}$ & $\mathrm{Ca}$ & $\mathbf{M g}$ & $\mathrm{S}$ \\
\hline & & & & $\cdots$ & $\ldots . \mathrm{k}$ & $a \ldots . .$. & ......... & \\
\hline \multirow[t]{5}{*}{ Oirã } & Folhas & 456,4 & 21,4 & 1,2 & 9,6 & 8,6 & 2,8 & 0,8 \\
\hline & Ramos & 1336,4 & 27,1 & 1,7 & 27,9 & 12,4 & 8,3 & 1,1 \\
\hline & Vagens & 587,0 & 23,5 & 1,2 & 8,9 & 1,9 & 1,6 & 1,0 \\
\hline & Sementes & 2350,0 & 141,2 & 10,4 & 16,4 & 2,1 & 6,1 & 5,0 \\
\hline & Total & 4729,9 & 213,2 & 14,5 & 62,8 & 25,0 & 18,8 & 7,9 \\
\hline \multirow[t]{5}{*}{ Poitara } & Folhas & 732,0 & 31,0 & 1,8 & 15,1 & 13,2 & 6,1 & 2,2 \\
\hline & Ramos & 1524,0 & 28,3 & 1,7 & 28,6 & 13,6 & 11,1 & 2,7 \\
\hline & Vagens & 550,0 & 15,8 & 0,7 & 6,4 & 1,4 & 1,1 & 1,2 \\
\hline & Sementes & 2200,0 & 129,1 & 8,6 & 13,8 & 1,1 & 5,3 & 6,5 \\
\hline & Total & 5006,0 & 204,2 & 12,8 & 63,9 & 29,3 & 23,6 & 12,6 \\
\hline \multirow[t]{5}{*}{ Tupã } & Folhas & 708,5 & 26,0 & 1,4 & 11,5 & 9,1 & 3,7 & 1,2 \\
\hline & Ramos & 1092,4 & 21,6 & 1,3 & 23,1 & 9,4 & 6,7 & 1,4 \\
\hline & Vagens & 600,0 & 20,9 & 0,9 & 8,5 & 2,0 & 1,6 & 1,0 \\
\hline & Sementes & 2400,0 & 103,2 & 10,1 & 18,0 & 3,1 & 7,0 & 5,5 \\
\hline & Total & 4600,9 & 171,7 & 13,7 & 61,1 & 23,6 & 19,0 & 9,1 \\
\hline \multirow[t]{5}{*}{ Penápolis } & Folhas & 477,0 & 17,0 & 2,3 & 6,2 & 8,7 & 3,9 & 0,8 \\
\hline & Ramos & 1349,0 & 22,8 & 0,9 & 19,9 & 13,8 & 8,4 & 1,6 \\
\hline & Vagens & 641,0 & 16,2 & 0,8 & 8,9 & 1,8 & 1,3 & 0,7 \\
\hline & Sementes & 1998,0 & 124,0 & 6,0 & 17,0 & 1,4 & 4,0 & 3,3 \\
\hline & Total & 4455,0 & 180,0 & 10,0 & 52,0 & 25,7 & 17,6 & 6,4 \\
\hline
\end{tabular}

Dentre os cultivares estudados, o cultivar IAC-Poitara absorveu maiores quantidades por unidade de área de potássio, cálcio, magnésio e enxofre. O cultivar IAC-Oirã absorveu maiores quantidades de nitrogênio e fósforo. No entanto, o cultivar IAC-Tupã direcionou mais eficientemente para a semente: o fósforo, o cálcio, o magnésio e enxofre (TABELA 3). 
TABELA 3. Porcentagem da matéria seca total produzida e da quantidade total de macronutrientes absorvida por quatro cultivares de amendoim durante o seu ciclo biológico, acumuladas nas sementes (média de 4 repetições).

\begin{tabular}{|c|c|c|c|c|c|c|c|}
\hline \multirow[b]{3}{*}{ Cultivares } & \multirow{3}{*}{$\begin{array}{c}\text { Matéria } \\
\text { seca }\end{array}$} & \multicolumn{6}{|c|}{ Índice de Área Foliar } \\
\hline & & \multicolumn{6}{|c|}{ Épocas (dias) } \\
\hline & & $\mathbf{N}$ & $\underline{P}$ & $\underline{\mathbf{K}}$ & $\mathrm{Ca}$ & $\mathrm{Mg}$ & $S$ \\
\hline Oirã & 49,7 & 66,2 & 71,7 & 26,2 & 8,4 & 32,6 & 51,6 \\
\hline Poitira & 43,9 & 63,2 & 66,8 & 21,5 & 3,7 & 22,3 & 51,4 \\
\hline Tupã & 52,2 & 61,0 & 73,2 & 29,4 & 13,2 & 36,5 & 61,0 \\
\hline Penápolis & 44,8 & 44,8 & 39,4 & 32,6 & 5,4 & 22,7 & 51,6 \\
\hline
\end{tabular}

TABELA 4. Quantidade acumulada de micronutrientes, em g/ha pelas diferentes partes da planta de quatro cultivares de amendoim, ao longo do ciclo biológico da cultura (média de 4 repetições).

\begin{tabular}{llccccc}
\hline \hline \multirow{2}{*}{ Cultivares } & Parte da & Planta & \multicolumn{5}{c}{ Nutrientes } \\
\cline { 3 - 6 } Oirã & & & Mn & Cu & Zn & B \\
\hline & Folhas & 332,8 & 1,2 & 9,6 & 8,6 & 2,8 \\
& Ramos & 669,5 & 1,7 & 27,9 & 12,4 & 8,3 \\
& Vagens & 875,8 & 1,2 & 8,9 & 1,9 & 1,6 \\
& Sementes & 157,4 & 10,4 & 16,4 & 2,1 & 6,1 \\
& Total & 2035,5 & 14,5 & 62,8 & 25,0 & 18,8 \\
& Folhas & 723,2 & 1,8 & 15,1 & 13,2 & 6,1 \\
& Ramos & 28,3 & 1,7 & 28,6 & 13,6 & 11,1 \\
& Vagens & 15,8 & 0,7 & 6,4 & 1,4 & 1,1 \\
& Sementes & 129,1 & 8,6 & 13,8 & 1,1 & 5,3 \\
& Total & 204,2 & 12,8 & 63,9 & 29,3 & 23,6 \\
& Folhas & 26,0 & 1,4 & 11,5 & 9,1 & 3,7 \\
& Ramos & 21,6 & 1,3 & 23,1 & 9,4 & 6,7 \\
& Vagens & 20,9 & 0,9 & 8,5 & 2,0 & 1,6 \\
& Sementes & 103,2 & 10,1 & 18,0 & 3,1 & 7,0 \\
& Total & 171,7 & 13,7 & 61,1 & 23,6 & 19,0 \\
& Folhas & 17,0 & 2,3 & 6,2 & 8,7 & 3,9 \\
& Ramos & 22,8 & 0,9 & 19,9 & 13,8 & 8,4 \\
& Vagens & 16,2 & 0,8 & 8,9 & 1,8 & 1,3 \\
& Sementes & 124,0 & 6,0 & 17,0 & 1,4 & 4,0 \\
& Total & 180,0 & 10,0 & 52,0 & 25,7 & 17,6 \\
\hline \hline
\end{tabular}


TABELA 5 - Porcentagem da quantidade total de micronutrientes absorvida por quatro cultivares de amendoim durante seu ciclo biológico, acumulada nas sementes (média de 4 repetições).

\begin{tabular}{lccccc}
\hline \hline Cultivares & $\mathrm{Fe}$ & $\mathrm{Mn}$ & $\mathrm{Cu}$ & $\mathrm{Zn}$ & $\mathrm{B}$ \\
\hline Oirã & 7,13 & 36,98 & 58,13 & 64,73 & 31,18 \\
Poitara & 3,17 & 24,55 & 42,68 & 58,52 & 36,00 \\
Tupã & 4,95 & 37,69 & 56,30 & 66,33 & 34,02 \\
Penápolis & 1,96 & 26,95 & 48,38 & 51,32 & 33,05 \\
Média & 4,45 & 31,54 & 51,37 & 60,22 & 33,56 \\
\hline \hline
\end{tabular}

Em média, os cultivares absorveram os macronutrientes, na seguinte ordem: nitrogênio $(192 \mathrm{~kg} / \mathrm{ha})$; potássio $(60 \mathrm{~kg} / \mathrm{ha})$; cálcio $(26 \mathrm{~kg} / \mathrm{ha})$; magnésio $(20 \mathrm{~kg} / \mathrm{ha})$; fósforo $(13 \mathrm{~kg} / \mathrm{ha})$ e enxofre (9kg/ha). Esses valores assemelham-se aos encontrados por RODRIGUES FILHO et al., (1986) com o cultivar Tatui-76 e são bem mais elevados do que os citados por COELHO \& TELLA (1967) com o cultivar Tatu.

O padrão de absorçãa dos macronutrientes, apresentado através das curvas nas Figuras 1, 2, 3 e 4 é praticamente o mesmo para os cultivares eretos (IAC-Tupã, Oirã e Poitara) e ligeiramente diferente para o cultivar rasteiro Penápolis, podendo-se recomendar a aplicação dos mesmos até no máximo aos 85 dias do ciclo biológico.

\section{Absorção e acúmulo de micronutrientes}

As quantidades acumuladas de micronutrientes pelos cultivares em estudo, no final do ciclo biológico, são apresentadas na TABELA 4. As Figuras 1, 2, 3 e 4 apresentam a marcha de absorção dos mesmos.

Verificou-se que o ferro é o elemento absorvido em maior quantidade por todos os cultivares e o cobre, o menos absorvido. $O$ cultivar IAC-Poitara absorveu ferro, manganês e boro em quantidades maiores do que os demais cultivares e o cultivar IAC-Oirã absorveu mais o cobre e o zinco.

O ferro é um micronutriente pouco translocado para a semente (em média $4,5 \%$ do total absorvido). O cobre e o zinco translocam $50,7 \%$ e $60,2 \%$ respectivamente do total absorvido para a semente. $O$ boro e o manganês são medianamente translocados para a semente $(31,4 \%$ e 33,5\%). Estes resultados podem ser vistos na TABELA 5.

A marcha de absorção dos micronutrientes (Figuras 1, 2, 3, 4) permite observar que o acúmulo dos mesmos acompanha o da matéria seca, ocorrendo valores máximos entre 85 e 100 dias do ciclo biológico, para todos os cultivares em estudo.

\section{CONCLUSÕES}

a) O padrão de crescimento e de partição da matéria seca dos cultivares de introdução recente IAC-Oirã, IAC-Poitara e IAC-Tupã é semelhante e diferente daquele cultivar Penápolis.

b) A diferença de produção entre os demais cultivares e o cultivar Penápolis não deve ser desprezada do ponto de vista econômico.

c) Os cultivares estudados tem padrão de utilização variáveis dos diferentes macro e micronutrientes, porém, absorvem maiores quantidades por unidade de área do que os cultivares citados na literatura.

\section{REFERÊNCIAS BIBLIOGRÁFICAS}

BATAGLIA, O.C.; FURLANI, A.M.C.; TEIXEIRA, J.P.F.; FURLANI, P.R.; GALLO, J.R. Métodos de analise química de plantas. Campinas: IAC, $48 \mathrm{p}$. 1983. (IAC. Boletim Técnico, 78).

COELHO, F.A.S.; TELLA, R. Absorção de nutrientes por planta de amendoim na cultura de primavera. Bragantia, Campinas, v.23, p.393-408. 1967. 
HUNT, R. Growth analysis of populations and communities. In: Plant growth analysis. London: Edward Arnold, 1981 cap.4, p.26-38.

KVET, J.; ONDOK, J.P.; NECAS, J.; JARVIS, P.G. Methods of Growth Analysis. In: SESTAK, Z, CATSKY, J.; JARVIS, P.G. (Ed). Plant Phothosynthetic Production. The Hague: W. Junk, 1971. cap.10, p.343-391. .

PEDRO JR., M.J.; BULISANI, E.A.; POMMER, C.V.; PASSOS, F.A.; GODOY, I.J.; ARANHA, C Instruções agrícolas para o Estado de São Paulo, Campinas: IAC, 1987. 231p. (IAC. Boletim 200).

POMPEU, A.S. IAC-Oirã, IAC-Poitara e IAC-Tupã: Novos cultivares de amendoim para o Estado de São Paulo. Bragantia, Campinas, v.46, n.1, p.127-131, 1987.
POMPEU, A.S.; GERIN, M.A.N.; PEREIRA, J.C.V.N.A.; BORTOLETTO, N.; YOKOYAMA, T.; HOJO, S. \& NAGAI, V. Estimativa da capacidade produtiva de novas linhagens de amendoim (Arachis hipogaea L.) no Estado de São Paulo. Ciência e Cultura. São Paulo, v.38, n.6, p.1075-1080. 1986.

RODRIGUES FILHO, F.S.O.; GODOY, I.J. \& FEITOSA, C.T. Acúmulo da matéria seca e nutrientes em plantas de amendoim cultivar Tatui-76. Revista Brasileira de Ciência do Solo, Campinas. v.10, p.61-66, 1986.

Enviado para publicação em 08.03 .93 Aceito para publicação em 06.05 .93 